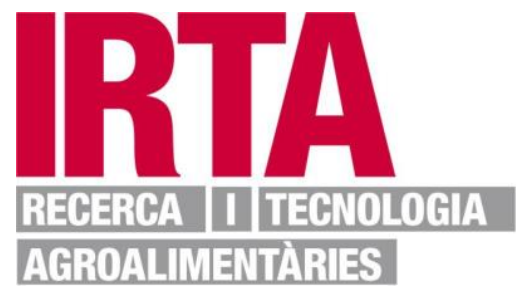

This document is a postprint version of an article published in Food Control (c) Elsevier after peer review. To access the final edited and published work see https://doi.org/10.1016/j.foodcont.2017.08.002

Document downloaded from:

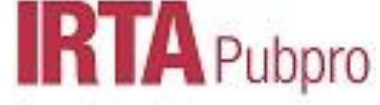

Open dgital archeve 


\section{Detection and identification of five common internal grain insect pests by multiplex}

\section{$2 \quad$ PCR}

3 Mireia Solà, Jordi Riudavets, Nuria Agusti*

4 IRTA, Ctra. Cabrils km 2, 08348 Cabrils, Barcelona, Spain.

$5{ }^{*}$ Corresponding author: IRTA, Ctra. Cabrils km 2, 08348 Cabrils, Barcelona, Spain. E6 mail address: nuria.agusti@irta.cat

8 Abstract

9 Consumer demands for better quality food have led to research on new tools aimed at 10 early detection of insect pests in agro food industries. In these industries, internal grain 11 feeders are the most concerning pests because of being the first colonizers of stored grain and transmitting harmful micro-organisms, such as fungi and bacteria, which affect both

13 food quality and human health. The immature stages of these cosmopolitan pests develop 14 and feed inside the grain kernels, easily evading visual analysis in food industries. To 15 avoid the consequent underestimation of contamination by internal pest species, a 16 multiplex PCR approach for the detection and identification of the five most concerning 17 primary pests that develop and feed hidden inside the grain kernels (Rhyzopertha dominica, Sitophilus granarius, S. oryzae, S. zeamais and Sitotroga cerealella) has been developed. Results have demonstrated that the designed protocol can be used for the diagnosis of grain contamination with high sensitivity ( 0.1 pupa/kilo of rice, except for $R$. dominica 10 pupae/kilo). This tool proved to be specific when 46 other species potentially present in grain commodities were tested, and to detect all developmental stages of S. zeamais in different kinds of grain (barley, maize, oat, spelt, rice and wheat) and pasta (macaroni). Detection was even possible when grain was treated with $\mathrm{CO}_{2}$. 
25 Finally, in order to confirm its applicability in food industries, this method has also been

26 tested in real commercial grain samples from a pasta mill. The multiplex PCR method

27 presented here could be of great help when making commercial decisions aimed at

28 satisfying the current market demands.

29 Keywords: insect pests, internal feeders, grain cereals, detection, identification, 30 multiplex PCR.

31 


\section{Introduction}

33

34

35

Cereal grain, either as raw or processed material, constitutes $80 \%$ of consumed food (Pimentel et al., 1997). Unfortunately, since the routine procedures before food consumption harbor several pest species, the safety and security of this food are susceptible to being affected when grain is stored, transported and processed (Hagstrum, Reed, \& Kenkel, 1999; Nopsa et al., 2015; Stejskal, Hubert, Aulicky, \& Kucerova, 2015). Phillips and Throne (2010) estimated post-harvest losses due to stored-product insects of between $9 \%$ and $20 \%$ or more in developed and developing countries, respectively.

Among insect pests, internal feeders, which are primary pest species that develop and feed inside the grain kernels, have generally been regarded as the most damaging pests of stored cereals (Toews, Campbell, Arthur, \& Ramaswamy, 2006). These species not only consume large quantities of grain, but are hidden inside the grain kernels during their preimaginal development. Furthermore, these insects facilitate grain contamination by secondary pests, which might increase the damage to the food by depositing faeces and cast skins. This all causes localized increases in heat and moisture that might lead to accelerated mold growth and mycotoxin production threatening the grain quality and human health (Beti, Phillips, \& Smalley, 1995; Phillips \& Throne, 2010; Shah \& Khan, 2014).

Because these internal feeders are not easily detected and removed during routine cleaning or processing practices, a situation where contamination is underestimated can often occur (Perez-Mendoza, Throne, Maghirang, Dowell, \& Baker, 2005; Toews, Campbell, Arthur, \& Ramaswamy, 2006). Hence, Storey, Sauer, Ecker, \& Fulk (1982) reported that $12 \%$ of wheat samples from export loads contained hidden internal insects in the United States. Consequently, it is not surprising that primary pests are mainly present in filth contamination of finished cereal products (Trematerra, Stejskal, \& Hubert, 
57 2011). The most concerning internal feeders in grain worldwide are the following five

58 species: Rhyzopertha dominica (F.) (Coleoptera: Bostrichidae); three species of the genus

59 Sitophilus (S. granarius (L.), S. oryzae (L.) and S. zeamais (Motschulsky) (Coleoptera:

60 Curculionidae)) and Sitotroga cerealella (Olivier) (Lepidoptera: Gelechiidae) (Castañé

61 \& Riudavets, 2015; Toews et al., 2007; Trematerra, Ianiro, Athanassiou, \& Kavallieratos,

62 2015). Also, Prostephanus truncatus (Horn) (Coleoptera: Bostrichidae), which is an

63 important internal feeder of stored maize and cassava, has also become a serious pest in 64 tropical and subtropical areas (CABI, 2017).

The increased consumer concerns about food safety and wholesomeness have produced a general trend toward a decrease in tolerance of live insects in food (Hagstrum, Reed, \& Kenkel, 1999; Trematerra, 2013). This situation has brought changes in grain standards in terms of food quality, which has emphasized the need for regulative approaches in the commercial sequence from the growers to consumers, driving market changes, politically and industrially (FDA, 1997; Stejskal, Aulicky, \& Kucerova, 2014). For example, domestic flour millers generally report zero tolerance for live insects, while the national agency in charge of food safety in the US, the Food \& Drug Administration (FDA), has produced administrative guidelines that set maximum levels for natural or unavoidable defects in food for humans (FDA, 1997). Because failure to control insect infestations when they initially occur in storage (or in the field) can lead to extensive contamination of the stored grain that could affect food security (Nopsa et al., 2015), the importance of establishing strategies for early diagnosis of insect contamination is evident.

With the purpose of detecting insect contamination, hazard analyses are routinely conducted in grain industries. At the moment, grain is inspected with sieves and all sorts of methods to crack kernels for the identification of insect adults, damaged kernels or 
82 insect fragments. However, when those visual methods are used alone, internal

83 infestations are not evident (Brader et al., 2002; Hubert, Nesvorna, \& Stejskal, 2009).

84 Additionally, insect fragments produced are not equivalent at each development stage of

85 the pest (immature stages and eggs have low to no chitin content, respectively),

86 highlighting the need for other analysis approaches (Brabec, Pearson, Flinn, \& Katzke

87 2010; Perez-Mendoza, Throne, Maghirang, Dowell, \& Baker, 2005).

Nowadays, there is a panoply of techniques available for insect detection

(Hagstrum \& Subramanyam, 2014; Neethirajan, Jayas, \& White, 2007; Parkin, 1956;

Phillips \& Throne, 2010; Trematerra, 2013). Unfortunately, although acoustic emissions,

ELISA, NIR and X-ray are diagnostic techniques that are capable of detecting hidden infestations (Chen \& Kitto, 1993; Fleurat-Lessard, Tomasini, Kostine, \& Fuzeau, 2006;

Fornal et al., 2007; Maghirang et al., 2003; Perez-Mendoza, Throne, Maghirang, Dowell,

\& Baker, 2005), they also present some limitations. Among their main drawbacks, some of these approaches do not accomplish the cost-time compromise, while others are less sensitive to low population densities (Neethirajan, Jayas, \& White, 2007; Nowaczyk et al., 2009).

In recent years, the application of molecular techniques has gained importance in food diagnostics because of their simplicity, speediness and specificity (ObrepalskaSteplowska, Nowaczyk, Holysz, Gawlak, \& Nawrot, 2008; Solà, Lundgren, Agusti, \& Riudavets, 2017). DNA-based approaches such as PCR have become relevant for the analysis of genetically modified organisms (GMOs) in food (Ciabatti, Froiio, Gatto, Amaddeo, \& Marchesi, 2006; Datukishvili, Kutateladze, Gabriadze, Bitskinashvili, \& Vishnepolsky, 2015), as well as for identifying insect species (Barcenas, Unruh, \& Neven, 2005; Zhang et al., 2016), providing an excellent method for both adult and immature forms even for sibling species (Correa, de Oliveira, Braga, \& Guedes, 2013; 
107 Hidayat, Phillips, \& FrenchConstant, 1996; Peng, Lin, Chen, \& Wang, 2002). Among

108 PCR approaches, the multiplex is the most suitable technique for screening multiple species because it is able to simultaneously identify all species present in a sample within a single PCR reaction (King et al. 2011; Solà, Agusti, \& Riudavets, 2015). It also offers

111 simplicity of execution, a reduction of carryover errors and time saving, compared to the 112 traditional singleplex PCR (Bai et al., 2009).

A multiplex PCR approach was here developed and described as a reliable

114 molecular method for routine detection and identification of the five main internal feeders

115 in grain samples, namely: the lesser grain borer ( $R$. dominica), the three grain weevils 116 species (S. granarius, S. oryzae, and S. zeamais) and the Angoumois grain moth ( $S$. 117 cerealella). One major consideration was to perform a large specificity test covering a 118 wide range of species potentially present in stored grain facilities. The sensitivity of this 119 protocol has been determined taking into consideration all developmental stages of the 120 insect pests (egg to adult), the post-mortem time, different grain types and the potential 121 of a grain treatment with modified atmospheres. Finally, some real commercial samples have been analyzed using the developed method.

\section{Material and methods}

\subsection{Biological material}

Five target pest species ( $R$. dominica, $S$. granarius, $S$. oryzae, $S$. zeamais and $S$. cerealella) were maintained in laboratory cultures at IRTA (Barcelona, Spain).

127 Coleopteran species were grown on organic rice (Eco-Salim, Maquefa, Spain), while the lepidoptera species was reared on maize (Crit d'or, Granollers, Spain). All insect cultures were maintained in climatic chambers at $28^{\circ} \mathrm{C}, 70 \% \mathrm{RH}$, and 16L: 8D. 
specimens of these non-target species were found in alimentary factory surveys since 1997 or came from laboratory colonies (Table 1). Identification of all species was performed using morphological keys before storing the specimens in alcohol $96^{\circ}$ or frozen at $-20^{\circ} \mathrm{C}$ until DNA extraction. of the protocol: brown rice and wheat (Eco-Salim, Maquefa, Spain), maize (Crit d'or,

137 Granollers, Spain), spelt (Biogrà, Polinyà, Spain), barley and oat (Celnat, Saint-GermainLaprade, France) and macaroni pasta (Castagno Bruno, Giaveno TO, Italy). In order to ensure that the food samples used in the analyses were insect-free, a sample of $125 \mathrm{~g}$ of each grain and pasta was maintained at $28{ }^{\circ} \mathrm{C}$, and $70 \% \mathrm{RH}$ for three months and checked for insect adult presence by sieving it with a $2 \mathrm{~mm}$ mesh. Also, for the same purpose, three samples of $5 \mathrm{~g}$ of each grain type and pasta were first ground with a laboratory grinder (Laboratory Mill 3303, Perten Instruments, Hägersten, Sweden) to be then analyzed for insect presence with the multiplex PCR described below.

\subsection{DNA extraction and multiplex PCR} extraction and another for the grain (infested or not). Insect DNA was extracted from whole individuals using a SpeedTools Tissue DNA extraction kit (Biotools, Madrid, Spain) and eluted in $100 \mu \mathrm{l}$ of $\mathrm{AE}$ buffer. In addition, $5 \mathrm{~g}$ (or $10 \mathrm{~g}$ in the case of the sensitivity test) of homogenized infested grain and pasta DNA was extracted with the Extragen Alimentos extraction kit (Sistemas Genómicos, Valencia, Spain) following the manufacturer's instructions and eluted in $1 \mathrm{ml}$ of purified water. One negative control was included in each DNA extraction group. DNA was stored at $-20{ }^{\circ} \mathrm{C}$ until PCR. 
155 Master Mix (Qiagen), $2 \mu 1$ of primer mix, $2 \mu 1$ of DNA template, $1 \mu l$ of purified water and $0.05 \mu \mathrm{l}$ of BSA [100 mg/ml]. Primer concentrations in the primer mix were different depending on the species (see Table 2). Samples were amplified in a 2720 thermal cycler (Applied Biosystems, CA, USA) for 35 cycles at $94{ }^{\circ} \mathrm{C}$ for $30 \mathrm{~s}, 60{ }^{\circ} \mathrm{C}$ for $90 \mathrm{~s}$ and $72{ }^{\circ} \mathrm{C}$ for $60 \mathrm{~s}$. An initial denaturation step was carried out at $95{ }^{\circ} \mathrm{C}$ for $15 \mathrm{~min}$ and a final extension step was performed at $72{ }^{\circ} \mathrm{C}$ for 10 min. Targeted DNA and water were always included as positive and negative control in the PCR, respectively. Obtained PCR products were run by electrophoresis in $1.5 \%$ agarose gel stained with ethidium bromide and visualized under UV light.

\subsection{Primer design and specificity}

Four pairs of species-specific primers were designed to target the mitochondrial cytochrome oxidase I (COI) region of the three Sitophilus species (S. granarius, S. oryzae and $S$. zeamais) and the moth $S$. cerealella. For that purpose, we first searched all the sequences present in the GenBank for each target species. When more than one sequence was found, they were aligned with ClustalW2 (www.ebi.ac.uk/Tools/msa/clustalw2).

170 Since all sequences showed a $100 \%$ of homology, we chose the largest one. Sequences selected for primers design of the four target species corresponded to the accession numbers: DQ200131, AY131101, AY131099 and AY131100 for S. cerealella, S.

173 granarius, S. oryzae and S. zeamais, respectively. These sequences, together with the one 174 of $R$. dominica (JQ989165) were aligned and compared for non-conserved regions. In the 175 case of $R$. dominica, a previously developed pair of primers (RdF1/RdR1), which 176 amplified a fragment of 286 bp, was used (Solà, Lundgren, Agusti, \& Riudavets, 2017). 
178 from our laboratory rearings. In order to confirm the detection of other populations of the 179 target species, additional analysis of individuals $(n=3)$ from other origins were also 180 performed. Populations tested were: three of $R$. dominica (one from Portugal, one from 181 Rumania and one from Turkey); and four of S. oryzae (one from Andalusia (Spain), one 182 from Portugal, one from France and one from Greece). Also, three individuals from the other 46 non-target species, except two individuals in two of them and one individual in one of them were tested (Table 1). To ensure the presence of DNA in those samples that gave a negative result, they were also amplified using universal primers as a positive control. The following universal pairs of primers were used depending on the species (see Table 1): ZBJ-ArtF1C/ZBJ-ArtR2C (Zeale, Butlin, Barker, Lees, \& Jones, 2011), UniMinibarF1/Uni-MinibarR1 (Meusnier et al., 2008) or LCO1490/HCO2198 (Folmer, Black, Hoeh, Lutz, \& Vrijenhoek, 1994). The DNA was amplified following the protocols described in those studies. If the expected fragment obtained using these universal pair of primers was not amplified, the specimen was not considered in the specificity analysis.

192 The designed primers sequences were also compared by performing a BLAST 193 (www.blast.ncbi.nlm.nih.gov/Blast.cgi) in order to find potential cross-reactions with 194 other species.

2.4. Characterization of the multiplex PCR: sensitivity, post-mortem detection, detection in different grains and in treated grain

To characterize the multiplex PCR method developed here, four tests were conducted: determination of the sensitivity threshold, determination of the post-mortem detection period, detection of larvae in different grains, and analysis of treated and untreated rice using S. zeamais eggs. In all experiments, insects were maintained in climatic chambers at $28{ }^{\circ} \mathrm{C}, 70 \% \mathrm{RH}$ and 16L: 8D. Three replicates consisting of three 
independent DNA extractions were tested in all experiments and each independent DNA extraction was tested up to three times, being considered positive if at least one of them was positive. In the sensitivity test, only one DNA extraction was conducted, which was also tested three times.

The sensitivity threshold of the multiplex PCR developed here was determined by

207 performing artificial infestations with the equivalent of $100,10,1$ and 0.1 pupae $/ \mathrm{kg}$ of rice. For that purpose, $20 \mathrm{~g}$ of rice infested with two pupae of each species was ground and used as a base for preparing all the insect infestation doses. The highest infestation dose tested (100 pupae/kg of rice) corresponded to a subsample of $10 \mathrm{~g}$ of this infested and ground grain. The remaining insect doses were obtained through serial mixtures of $90 \mathrm{~g}$ of ground insect-free rice homogenized with $10 \mathrm{~g}$ of ground infested grain from the preceding infestation dose. Therefore, the highest infestation dose corresponded to a sample of $10 \mathrm{~g}$ of infested grain, while the rest consisted in subsamples of $10 \mathrm{~g}$ extracted from $100 \mathrm{~g}$ of infested grain.

In order to determine the post-mortem detection period, five adults (one of each target species) killed by freezing at $-80{ }^{\circ} \mathrm{C}$ for 20 minutes were maintained for different periods in small vials with some rice at $28{ }^{\circ} \mathrm{C}, 70 \% \mathrm{RH}$ and 16L: $8 \mathrm{D}$ to allow DNA degradation. After, 0, 30, 90, 150, 365, 548 and 760 days, insects were frozen at $-20^{\circ} \mathrm{C}$ until DNA extraction to stop their degradation.

Insect detection in different kinds of grain was tested by conducting artificial infestations of $S$. zeamais adults in six different grains: barley, maize, oat, spelt, rice and wheat, as well as in pasta (macaroni). For that purpose, $250 \mathrm{~g}$ of organic cereal or pasta was infested with 10 adults of $S$. zeamais and maintained for 15 days in the climatic chamber in the same conditions described above. Then, grain was sieved with a $2 \mathrm{~mm}$ 
mesh to collect the adults and divided into two portions of $125 \mathrm{~g}$; one was ground and

227 frozen for molecular analysis, while the other one was maintained in the climatic chamber 228 (same conditions) for 40 days. The S. zeamais adults that emerged from the second 229 portion of grain were counted after sieving as a way to estimate the number of hidden 230 larvae present in the first portion used for molecular analysis. zeamais eggs in treated, as well as in untreated, grain, $1.5 \mathrm{~kg}$ of brown rice was infested with $10 \mathrm{~S}$. zeamais adults. One week later, the infested rice was sieved to eliminate the introduced adults and divided into three equal parts. Two portions were treated with a modified atmosphere of $90 \% \mathrm{CO}_{2}$ for 12 days before grinding. This $\mathrm{CO}_{2}$ dose is known to be efficient for killing eggs of these species (Riudavets, Castañé, Alomar, Pons, \& Gabarra, 2009). The third portion remained untreated. This one and one of the previously treated portions were ground and frozen at $-20{ }^{\circ} \mathrm{C}$ until DNA extraction. The other treated portion was maintained for 40 days under the same controlled conditions as above to check for the presence of adults.

\subsection{Analysis of commercial samples}

Some commercial grain samples from a real Spanish industry were analyzed for the presence of the five target species using the developed multiplex PCR method. These grain samples came from the routine procedure of this industry when new grain arrives from the field to be processed. This procedure consists in taking a portion of $1 \mathrm{~kg}$ of grain and sieving it to check for insect presence. Then, the same $1 \mathrm{~kg}$ of grain samples were

247 sent to our laboratory for further analyses. Once in the laboratory, all samples were first

248 sieved with a $2 \mathrm{~mm}$ mesh and the obtained insects were counted and identified. Then, each sample was divided into two equal portions of $500 \mathrm{~g}$; one was ground and frozen at 
$-20^{\circ} \mathrm{C}$ for molecular analysis, while the other one was maintained for at least 40 days in

251 the climatic chamber (same conditions as above) to check for adult insect presence after this period of time. Five commercial samples originally from France (one from $20^{\text {th }}$ May and one from $31^{\text {st }}$ May 2016) were analyzed in total. Three replicates consisting of three independent subsamples of $5 \mathrm{~g}$ were analyzed by multiplex PCR per each of the samples received, except for one of the samples from $14^{\text {th }}$ March 2016, where only 2 multiplex PCR where carried out. Each sample was considered positive when at least one out of three of these subsamples was positive for insect presence.

\subsection{Data analysis}

DNA amplification observed in the agarose gels was scored as 1 or 0 according to the presence or absence of the expected band, respectively. Then, the frequency of the positive amplification was calculated. For the sensitivity test and the analysis of postmortem detection, a logistic regression to the data was performed with JMP® (Version 8.0.1). In the sensitivity test, pest species and infestation dose were used as sources of variation, while in the post-mortem analysis, time and species were the selected factors. The relationship between the results obtained by sieving and by multiplex PCR to diagnose insect presence in commercial samples was studied with a Pearson's correlation using SigmaPlot (Systat Software, San Jose, CA).

\section{Results}

\subsection{Primer specificity}

The multiplex PCR developed here using the five species-specific primer pairs successfully amplified the expected amplicons (Fig. 1) when our laboratory rearing specimens were tested. In the case of $S$. oryzae, some specimens amplified two bands, the 
274 expected one of $213 \mathrm{bp}$ and a faint one smaller than $151 \mathrm{bp}$. Nevertheless, the 275 amplification of all S. oryzae specimens tested led to the same pattern and did not interfere 276 with the identification of the other four target species. When specimens of S. oryzae and

$277 R$. dominica from other origins (different populations) were tested, all of them were also 278 amplified.

When the other 46 insect species were tested with the designed multiplex PCR, only the five target species showed the expected band, proving a high specificity for the five target species (Table 1). It is a major consideration that when those 46 species that gave a negative amplification with the designed protocol were tested using insect universal primers, they all gave a positive amplification, thereby demonstrating the presence of insect DNA. When the potential cross-reactivity of the designed primers with sequences of other species was tested by performing a BLAST, the only species identified using both forward and reverse designed primers were the target species with a $100 \%$ of matches and an e-value $<1$. The only exception was the pair of primers of $S$. granarius, which also matched Ichneumonidae sp., which are not pest species of stored products.

3.2. Characterization of the designed multiplex PCR: sensitivity, post-mortem detection, detection in different grains and in treated grain When different artificial infestation doses $(100,10,1$ and 0.1 pupae of each species $/ \mathrm{kg}$ of rice) were tested to determine the sensitivity of the multiplex PCR, the sensitivity threshold was determined on the doses of 0.1 pupa per kilo of rice for the three

294 Sitophilus species and $S$. cerealella, while $R$. dominica was detected up to 10 pupae per kilo of rice (Table 3; Fig. S1). DNA amplification among infestation doses did not present statistical differences $\left(\chi^{2}=5.99, \mathrm{DF}=3, P=0.112\right)$. However, the DNA diagnosis differed among the internal feeder species $\left(\chi^{2}=14.92, \mathrm{DF}=4, P=0.005\right)$. 
The analysis of a mixture of five adults (one from each target species) killed at 0 ,

299

300

301

302

303

304

305

306

307

308

309

310

311

312

313

314

315

316

317

318

319

320

321

322

$30,90,150,365,548$ and 760 days showed a post-mortem detection period of 365 days. After 548 days, this molecular method was less able to detect DNA from $S$. granarius and

R. dominica. However, S. cerealella, S. zeamais and S. oryzae were still detected up to 760 days (more than two years) after insect death (Table 3; Fig. S2). The logistic regression performed showed that the time post-mortem and the insect species affected significantly the insect diagnosis $\left(\chi^{2}=22.23, \mathrm{DF}=5, P=0.0005\right.$ and $\chi^{2}=18.28, \mathrm{DF}=4$, $P=0.0011$, respectively).

The DNA of $S$. zeamais was successfully amplified in all the artificial infestations conducted in $250 \mathrm{~g}$ of different grains (barley, maize, oat, spelt, rice and wheat) and pasta (macaroni) with 10 adults of this species for 15 days. These positive results were corroborated when 121, 104, 147, 135 and 156 S. zeamais adults were obtained in rice, wheat, oat, barley and spelt, respectively, after sieving the portion maintained under controlled conditions for 40 days. Because no insect adults were obtained in maize, three subsamples of $5 \mathrm{~g}$ of a ground mixture of 130 S. zeamais adults (the average of the insects' offspring obtained in the other grains) in $125 \mathrm{~g}$ of this maize were analyzed by multiplex PCR. The analysis of the maize showed S. zeamais DNA amplification (Fig. S3). Similarly, no adults, and only seven small larvae, were obtained in the macaroni pasta. For this reason, we replaced seven insect-free macaroni from the molecular portion with these seven infested macaroni from the climatic chamber portion. The analysis of the portion destined to molecular diagnosis by multiplex PCR confirmed the ability of the technique to detect the immature S. zeamais in the artificially infested pasta (Fig. S3). On the other hand, when the non-infested $250 \mathrm{~g}$ portion maintained under controlled conditions was sieved, no insect adult was observed. Also, when the non-infested $250 \mathrm{~g}$ portion used for the molecular analysis was tested by multiplex PCR, no DNA 
323

324

325

326

327

328

329

330

331

332

333

334

335

336

337

338

339

340

341

342

343

344

345

346

347

amplification was obtained either. This confirmed that before manipulation, cereals and pasta where insect free.

Finally, when brown rice infested with $S$. zeamais and treated with $90 \% \mathrm{CO}_{2}$ for 12 days; and not treated brown rice infested with $S$. zeamais were analyzed by multiplex PCR, S. zeamais infestations were detected in both cases. As expected, no S. zeamais adults were obtained from the treated grain portion maintained in the climatic chamber for 40 days.

\subsection{Analysis of commercial samples}

The molecular analysis of the grain samples from a Spanish industry was coherent with the results obtained by sieving in the same industry. The five samples which were received the following dates: $20^{\text {th }}$ May 2015, $29^{\text {th }}$ May 2015, two from $14^{\text {th }}$ March 2016, and $31^{\text {st }}$ May 2016, were again sieved in the laboratory and divided into two portions: one for adult emergence and the other one for molecular analysis. We were informed by the industry that two of them were positive for Sitophilus spp. adults. They were the samples from $29^{\text {th }}$ May 2015 and $31^{\text {st }}$ May 2016. After sieving these two samples in the laboratory, one and six Sitophilus spp. adults were obtained, respectively. Forty days later, another sieving was performed and two Sitophilus spp. adults were observed in both samples. The molecular analysis of these samples showed that they were $S$. oryzae. More specifically, in the first sample, the three subsamples gave a positive result for S. oryzae, while in the second sample, two positives were obtained for this species out of three subsamples. The rest of the samples (20th May 2015, 14th March 2016 a and b) were negative for insect presence in the industry, as well as in our laboratory, after sieving twice and after performing the multiplex PCR. Moreover, results obtained by sieving (either in the industry or in the laboratory) were highly correlated with the results obtained by multiplex PCR ( $\mathrm{r}=0.86, \mathrm{DF}=12, P<0.0001)$. In fact, when a sample was considered negative after 
sieving, was always negative by multiplex PCR. On the other hand, a positive result

349 obtained by sieving, was also positive by multiplex PCR in the $83 \%$ of the occasions.

350

351

352

353

354

355

356

357

358

359

360

361

362

363

364

365

366

367

368

369

370

371

\section{Discussion}

In the present study, a multiplex PCR protocol has been developed to detect primary pest species in grain, offering significant advantages for routine analysis. This protocol showed high sensitivity by successfully detecting 0.1 pupa from $S$. granarius, $S$. oryzae, S. zeamais and and S. cerealella per 1 kilo of rice (1 pupa per 10 kilos) and 10 pupae per kilo of rice in the case of $R$. dominica. This sensitivity threshold is similar to or even overpasses the regulatory standards for insect presence in food factories or commercial trade standards using the most common detection techniques. These defect action levels are commonly based on macro-analytical visual detection of adults, insect fragments or insect-damaged kernels (IDKs) (Chen \& Kitto, 1993). In addition, Toews et al. (2007) and Perez-Mendoza, Throne, Maghirang, Dowell, \& Baker (2005) demonstrated that near-infrared reflectance spectroscopy (NIRS), one of the techniques used for insect detection, shows an important variability when analyzing samples with fewer than 100 insect fragments per kilo of wheat flour, and was unable to reach the quality standard set by the FDA (75 insect fragments per $50 \mathrm{~g}$ of wheat flour) (Brabec, Pearson, Flinn, \& Katzke, 2010). On the other hand, X-ray, which is an official standard method in the USA (Fornal et al., 2007), despite appearing to have the greatest potential for being introduced in the food industry for insect detection (Neethirajan, Jayas, \& White, 2007), is not sensitive enough to accurately detect eggs and small larvae (Karunakaran, Jayas, \& White, 2003). Similarly, note that in the diagnosis of insect presence based on IDKs, the damage caused by insect eggs or small larvae is null or inappreciable. 
373 techniques in grain industries as a tool for diagnosing insect presence. Solà, Lundgren, 374 Agusti, \& Riudavets (2017) reached sensitivity thresholds of 13 eggs/small larvae, 0.1

375 big larvae/pupae and 0.02 adults of $R$. dominica per kilo of rice, using quantitative PCR 376 (qPCR). Alternatively, Obrepalska-Steplowska, Nowaczyk, Holysz, Gawlak, \& Nawrot 377 (2008) reached a sensitivity threshold equivalent to 0.01 S. granarius adults per kilo of 378 wheat flour using qPCR. This information might help managers from the food industry make decisions about rejecting batches, storing grain, using control measures, processing grain or transporting it to another market outlet with less stringent standards (Brabec et al., 2010; Hagstrum, Reed, \& Kenkel, 1999). However, molecular approaches, although they are able to detect all life stages of the target primary pests, are not able to discriminate among life stages in mixed populations. This could be a drawback since stored grain usually has insect pests of mixed ages. Although it is not essential to determine the developmental stage of the pests for grain grading, the precision of insect developmental stages could help to make the most of management decisions on processing the grain 387 (Dowell, 1998).

Degradation of the DNA of dead organisms increases with time post-mortem and this might hamper a successful DNA amplification. For this reason, the detection range of the five target insect species has been determined by analysing several periods after insect death, showing that the developed multiplex PCR was able to detect adults of the five pest species even one year after death. After this period of time, the technique was not able to detect DNA from $S$. granarius or $R$. dominica, but was still able to detect $S$. cerealella, S. zeamais and S. oryzae even after two years. The bigger size of the amplified amplicons for $S$. granarius and $R$. dominica could be the reason for losing their detection earlier. The detection of immature $S$. zeamais DNA in $\mathrm{CO}_{2}$-treated grain samples also 
shows the ability of the technique to detect dead immature stages of $S$. zeamais, and suggests that this might be the case for the other target species. The fact that dead insects can be detected for long periods of time has positive and negative aspects. On the one hand, the detection of dead insects provides an idea of the contamination in the analyzed grain, even in the past. On the other hand, the inability to discriminate between dead and alive insects could lead to an overestimation of the control measures needed with a consequent overtreatment of the grain (Solà, Lundgren, Agusti, \& Riudavets, 2017). This method enhances the accuracy of the identification of insects based on their specific detection. Because different species have different behaviors and cause different levels of grain loss requiring different approaches to control them (Cao et al., 2015), in

407 this work we have developed a multiplex PCR protocol rather than a singleplex PCR approach (Solà, Agusti, \& Riudavets, 2015). This enhanced the specific and simultaneous identification of the five target pest species by easily recognizing the precise bands of different molecular weights in the agarose gels (Fig. 1). The universality of the designed

411 primers is suggested by the positive detection of other populations of $S$. oryzae and $R$. 412 dominica with different origins, as well as for the high homology that presented the 413 sequences of all populations of each target species present in GenBank. Nevertheless, in 414 the case that in future tests other populations of the five target species different from those tested in this study may be present, we recommend to conduct a previous specificity test in order to confirm the correct amplification of the target species population. The cross-

417 reactivity test performed with the 51 species potentially present in stored and 418 agroecosystem environments (Table 1) ensured the specific identification of only the target species. The potential cross-reactivity of the designed primers tested by performing a BLAST also demonstrated their high specificity. 
The immature stages of some of these species are particularly difficult to recognize, as in the case of the three Sitophilus species studied here. Although most identification procedures rely on the morphological characterization of the adults, in the case of sibling species, such as $S$. oryzae and $S$. zeamais, this is tedious and needs the expertise of a taxonomist and the use of microscopy techniques (Hidayat, Phillips, \& FrenchConstant, 1996; Peng, Lin, Chen, \& Wang, 2002). Using the multiplex PCR designed here, we succeeded not only in distinguishing the Sitophilus adults, as achieved in other studies (Correa et al., 2013; Hidayat, Phillips, \& FrenchConstant, 1996; Peng, Lin, Chen, \& Wang, 2002), but also simultaneously recognizing immature stages of these sibling species in a single PCR reaction.

On the other hand, it is well known that $S$. oryzae is more resistant to phosphine, which is one of the most commonly used chemical insecticides in stored grain worldwide, than its sibling species, S. zeamais (Hagstrum, Reed, \& Kenkel, 1999). Therefore, the use of the present PCR method would help managers use appropriate control measures according to the species present. Usually, only insect eggs or first-instar larvae are present after fumigation (Brabec, Pearson, Flinn, \& Katzke, 2010). Thus, since routine analysis techniques are based on visual lures, those infestations may evade diagnosis and then the storability of the grain may be underestimated.

We have also demonstrated success in detecting $S$. zeamais eggs in rice after a treatment with $\mathrm{CO}_{2}$ for 12 days, suggesting that this method would also detect other

441 developmental stages of the other four target species after a treatment of this kind, thereby 442 avoiding future increases of pest populations and therefore decreasing the grain 443 downgrade. In this respect, the use of the present protocol would help managers to 444 fumigate only once infestations reached a critical density (commonly considered to be more than two insects/kg of grain) (Flinn, Hagstrum, Reed, \& Phillips, 2010) and avoid 
unnecessary treatments based on standard calendars (Trematerra, 2013). This would be

447 in line with the increasing public concerns beyond the overuse of agricultural chemicals

448 that are harmful to the environment and human health (Bulathsinghala \& Shaw, 2013)

449 and would prevent the development of insect resistance due to continuous fumigation

450 (Hagstrum \& Subramanyam, 2014; Phillips \& Throne, 2010).

451 The dominant grain crops grown worldwide are rice, wheat, maize, millet, barley

452 and rye (Pimentel et al., 1997), and internal feeders are frequently found in all of them

453 when grain is stored. For this reason, we have tested the detection of the five target insect

454 pests in most of those grains. As a model, we tested the detection of larvae of S. zeamais

455 in rice, wheat, maize, oat, spelt and barley. Since these grains are usually processed before

456 consumption, in order to ensure that insects are also detected in processed grain we

457 analyzed the presence of this weevil in macaroni pasta. The results obtained showed that

458 the method was able to detect immature stages of $S$. zeamais in all these grains and in

459 pasta, thereby suggesting that this multiplex PCR method would also detect all

460 developmental stages of the five target species.

The fact that no weevil offspring was observed in the infested maize highlights

the global effort to select varieties resistant to insect presence in the most valuable grain crops (Abebe, Tefera, Mugo, Beyene, \& Vidal, 2009). Nevertheless, the ability of the present method to detect insects in maize was demonstrated with the amplification of the expected band for S. zeamais in the agarose gel when analyzing samples consisting in a ground mixture of weevil adults and maize. On the other hand, only seven small larvae were obtained from the macaroni pasta when sieving. A comparison of this number with the others obtained from the rest of the grains (an average of 132 insect adults) reveals that although $S$. zeamais can lay eggs inside pasta, this substrate is not the most suitable

470 for the development of this pest in comparison to the other grain cereals tested. 
Insect infestations can occur during the storage process in manufacturing

472 facilities, warehouses, general stores and retail shops, but insects can colonize food at any

473 processing step, providing situations where insects might reach consumers (Jayas, White,

$474 \&$ Muir, 1995). The stability of DNA, which can withstand temperatures of pasteurization

475 and sterilization (Laube et al., 2007), suggests that the use of molecular approaches as a

476 diagnostic technique in food factories would enable unambiguous identification of insects

477 in food at any processing point. However, further studies should be conducted in order to

478 corroborate this statement, particularly after the manufacturing process of pasta. This

479 might be an advantage, particularly ahead of approaches based on proteins such as

480 ELISA, where false-positive situations can occur due to the denaturation of proteins at

481 temperatures above $56^{\circ} \mathrm{C}$ (Velebit, Markovic, Jankovic, \& Borovic, 2009).

After analyzing commercial samples from a grain industry, results obtained by multiplex PCR were in accordance with those obtained by the operator of the industry. This demonstrates the potential of this molecular method for being introduced in processing industries for diagnosing insect presence. PCR-based methods are commonly accepted and recommended for food quality control, such as the detection of GMOs or for food traceability (Bai et al., 2009; Laube et al., 2007). In this sense, the detection of non-desired insects in food by molecular tools is suitable as a food control measure as has already been suggested by Obrepalska-Steplowska, Nowaczyk, Holysz, Gawlak, \& 490 Nawrot (2008), Solà, Riudavets, \& Agusti (2015) and Solà, Lundgren, Agusti, \& Riudavets (2017). infestations is often inaccurate because insect infestations are not homogeneous in grain facilities. Nevertheless, the present method identifies insect infestations with high accuracy and sensitivity when grain is thoroughly homogenized. However, in order to 
ensure that the obtained information is representative of the real grain contamination, it

497 is important to establish an adequate number of samples of a determinate size (Jian, Jayas,

498 \& White, 2014a, b). Once samples are defined, the transmission of this information to grain managers in food industries should help them to implement IPM practices, develop economic thresholds and set up decision-making strategies aimed at using pesticides more selectively and thus be more environmentally friendly while at the same time preventing the undesired presence of insects in food. Additionally, the combination of the present multiplex PCR with a qPCR protocol for the detection of particular pest species, such as those developed by Solà, Lundgren, Agusti, \& Riudavets (2017) and Obrepalskascreenshot of the grain status. Therefore, further work is needed to combine simultaneous identification of concerned primary pests with the quantification of real populations.

\section{Conclusions}

In this study, a multiplex PCR approach is described for the detection and

511 identification of the five main primary pests that develop inside grain cereals ( $R$.

512 dominica, S. granarius, S. oryzae, S. zeamais and S. cerealella). This method has

513 demonstrated the ability to detect internal stages of the target pests, a characteristic that

514 the most common techniques such as sieving lack. This approach is a reliable technique 515 for simultaneously and specifically identifying the five concerned internal feeders with 516 high sensitivity ( 0.1 pupa per kilo of rice, or 10 pupae in the case of $R$. dominica), even 517 one year after death. With the detection of hidden immature stages of $S$. zeamais in 518 different kinds of grain (barley, oat, spelt, rice, wheat) and pasta, even when the grain is 519 treated it is expected that this method will detect all target species present. The results 
520 obtained for the analysis of some real commercial samples with the developed multiplex

521 PCR method suggest that the use of the developed multiplex PCR in food control analyses 522 for insect detection and identification would improve the quality of food and satisfy most 523 consumer concerns.

\section{Acknowledgements}

This research was funded by the Instituto Nacional de Investigación Agraria

527 (INIA) with projects RTA2011-00025-CO2-O1 and RTA2014-00006-C02-01. We also acknowledge funding from the CERCA Programme/Generalitat de Catalunya. Additionally, we would like to thank J. Mas and J. A. Gonzalez from Productos Alimenticios Gallo S.L. (Spain) for providing the commercial samples tested in this study. M. Solà was supported by an FPI grant also funded by the INIA.

\section{References}

Abebe, F., Tefera, T., Mugo, S., Beyene, Y., \& Vidal, S. (2009). Resistance of maize varieties to the maize weevil Sitophilus zeamais (Motsch.) (Coleoptera: Curculionidae). African Journal of Biotechnology, 8(21), 5973-5943.

Bai, W., Xu, W., Huang, K., Yuan, Y., Cao, S., \& Luo, Y. (2009). A novel common primer multiplex PCR (CP-M-PCR) method for the simultaneous detection of meat species. Food Control, 20, 366-370.

Barcenas, N. M., Unruh, T. B., \& Neven, L. G. (2005). DNA diagnostics to identify internal feeders (Lepidoptera : Tortricidae) of pome fruits of quarantine importance. Journal of Economic Entomology, 98, 299-306. 
543 Beti, J. A., Phillips, T.W., \& Smalley, E. B. (1995). Effects of maize weevils (Coleoptera: Curculionidae) on production of aflatoxin B1 by Aspergillus flavus in stored corn. Journal of Economic Entomology, 88(6), 1776-1782.

Brabec, D., Pearson, T., Flinn, P., \& Katzke, D. (2010). Detection of internal insects in wheat using a conductive roller mill and estimation of insect fragments in the resulting flour. Journal of Stored Products Research, 46, 180-185.

Brader, B., Lee, R. C., Plarre, R., Burkholder, W., Kitto, G. B., Kao, C., et al.. (2002). A 550 comparison of screening methods for insect contamination in wheat. Journal of Stored Products Research, 38, 75-86.

Bulathsinghala, A. T., \& Shaw, I. C. (2013). The toxic chemistry of methyl bromide. Human \& Experimental Toxicology, 33, 81-91.

CABI. (2017). Available from: http://www.cabi.org/isc/datasheet/44524

Cao, Y., Zhang, C., Chen, Q., Li, Y., Qi, S., Tian, L., \& Ren, Y. (2015). Identification of species and geographical strains of Sitophilus oryzae and Sitophilus zeamais using the visible/near-infrared hyperspectral imaging technique. Pest Management Science, 71, 1113-1121.

Castañé, C., \& Riudavets, J. (2015). Sampling arthropod pests and natural enemies in stored barley. Journal of Stored Products Research, 64, 54-61.

561 Chen, W., \& Kitto, G. B. (1993). Species-specific immunoassay for Sitophilus granarius in wheat. Food and Agricultural Immunology, 5, 165-175.

563 Ciabatti, I., Froiio, A., Gatto, F., Amaddeo, D., \& Marchesi, U. (2006). In-house validation and quality control of real-time PCR methods for GMO detection: a practical approach. Developments in Biologicals, 126:79-86. 
Correa, A. S., de Oliveira, L. O., Braga, L. S., \& Guedes, R. N. C. (2013). Distribution of the related weevil species Sitophilus oryzae and S. zeamais in Brazil. Insect Science, 20, 763-770.

Datukishvili, N., Kutateladze, T., Gabriadze, I., Bitskinashvili, K., \& Vishnepolsky, B. (2015). New multiplex PCR methods for rapid screening of genetically modified organisms in foods. Frontiers in Microbiology, 6, 757.

Dowell, F. E. (1998). Automated color classification of single wheat kernels using visible and near-infrared reflectance. Cereal Chemistry, 75, 142-144.

[FDA] Food and Drug Administration (1997), 578.450, Wheat \& flour adulteration with insect fragments and rodent hairs (CPG 7104.06). Compliance Policy Guides Manual, Chapter 5, Foods, color and cosmetics, Subchapter 578 - processed grain. (http://www.fda.gov/ora/ compliance_ref/cpg/default.htm\#1998).

Fleurat-Lessard, F., Tomasini, B., Kostine, L., \& Fuzeau, B. (2006). Acoustic detection and automatic identification of insect stages activity in grain bulks by noise spectra processing through classification algorithms. Lorini, I., Bacaltchuk, B., Beckel, H., Deckers, D., Sundfeld, E., Dos Santos, J.P., Biagi, J.D., Celaro, J.C., D’A Faroni, L.R., Bortolini L., Sartori, M.R, Elias, M.C., Guedes, R.N.C., Da Fonseca, R.G., Scussel, V.M. (eds.), Proceedings of the 9th International Working Conference on Stored Product Protection, 476-186. 15 to 18 October 2006, Campinas, São Paulo, Brazil. Brazilian Post-harvest Association - ABRAPOS, Passo Fundo, RS, Brazil, 2006. (ISBN 8560234004).

Flinn, P. W., Hagstrum, D. W., Reed, C., \& Phillips, T. W. (2010). Insect population dynamics in commercial grain elevators. Journal of Stored Products Research, $46,43-47$. 
590 Folmer, O., Black, M., Hoeh, W., Lutz, R., \& Vrijenhoek, R. (1994). DNA primers for

591

592

593

594

595

596

597

598

599

600

601

602

603

604

605

606

607

608

609

610

611

612

613

614 amplification of mitochondrial cytochrome $\mathrm{c}$ oxidase subunit I from diverse metazoan invertebrates. Molecular Marine Biology and Biotechnology, 3, 294-9.

Fornal, J., Jelinski, T., Sadowska, J., Stanislaw, G., Nawrot, J., Niewiada, A., et al. (2007). Detection of granary weevil Sitophilus granarius (L.) eggs and internal stages in wheat grain using soft X-ray and image analysis. Journal of Stored Products Research, 43, 142-148.

Hagstrum, D. W., Reed, C., \& Kenkel, P. (1999). Management of stored wheat insect pests in the USA. Integrated Pest Management Reviews, 4, 127-143.

Hagstrum, D. W., \& Subramanyam, B. (2014). A review of stored-product entomology information sources. American Entomologist, 55, 174-183.

Hidayat, P., Phillips, T. W., \& FrenchConstant, R. H. (1996). Molecular and morphological characters discriminate Sitophilus oryzae and S-zeamais (Coleoptera: Curculionidae) and confirm reproductive isolation. Annals of the Entomological Society of America, 89, 645-652.

Hubert, J., Nesvorna, M., \& Stejskal, V. (2009). The efficacy of sieving, filth flotation and Tullgren heat extraction for detecting various developmental stages of Tribolium castaneum and Ephestia kuehniella in samples of wheat grain, flour and semolina. Journal of Stored Product Research, 45, 279-288.

Jayas, D.S., White, N.D.G \& Muir, W. E. (1995). Stored-Grain Ecosystems. Marcel Dekker Inc. New York.

Jian, F., Jayas, D. S., \& White, N. D. G. (2014a). How many kilograms of grain per sample unit is big enough? Part I - Comparison of insect detection and density estimation between manual probe sampling and Insector (R) system. Journal of Stored Products Research, 56, 60-66. 
615 Jian, F., Jayas, D. S., \& White, N. D. G. (2014b). How many kilograms of grain per sample unit is big enough? Part II - Simulation of sampling from grain mass with different insect densities and distribution patterns. Journal of Stored Products Research, 56, 67-80.

Karunakaran, C., Jayas, D. S.J., \& White, N. D. G. (2003). X-ray image analysis to detect infestations caused by insects in grain. Cereal Chemistry, 80, 553-557.

621

622

623

624

625

626

627

628

629

630

631

632

633

634

635

636

637

King, R. A., Moreno-Ripoll, R., Agusti, N., Shayler, S. P., Bell, J. R., Bohan, D.A., \& Symondson, W. O. C. (2011). Multiplex reactions for the molecular detection of predation on pest and nonpest invertebrates in agroecosystems. Molecular Ecology Resources, 11, 370-373.

Laube, I., Zagon, J., Spiegelberg, A., Butschke, A., Kroh, L. W., \& Broll, H. (2007). Development and design of a 'ready-to-use' reaction plate for a PCR-based simultaneous detection of animal species used in foods. International Journal of Food Science and Technology, 42, 9-17.

Maghirang, E. B., Dowell, F. E., Baker, J. E., \& Throne, J. E. (2003). Automated detection of single wheat kernels containing live or dead insects using near-infrared reflectance spectroscopy. Transactions of the Asae, 46, 1277-1282.

Meusnier, I., Singer, G. A., Landry, C.J.-F., Hickey, D. A., Hebert, P. D. N., \& Hajibabaei, M. (2008). A universal DNA mini-barcode for biodiversity analysis, Bmc Genomics, 9.

Neethirajan, S., Jayas, D. S., \& White, N. D. G. (2007). Detection of sprouted wheat kernels using soft X-ray image analysis. Journal of Food Engineering, 81, 509513. 
638 Nopsa, J. F. H., Daglish, G. J., Hagstrum, D. W., Leslie, J. F., Phillips, T. W., Scoglio, C., et al. (2015). Ecological networks in stored grain: Key postharvest nodes for emerging pests, pathogens, and mycotoxins. Bioscience, 65, 985-1002.

Nowaczyk, K., Obrepalska-Steplowska, A., Gawlak, M., Throne, J. E., Olejarski, P., \& Nawrot, J. (2009). Molecular techniques for detection of tribolium confusum

Obrepalska-Steplowska, A., Nowaczyk, K., Holysz, M., Gawlak, M., \& Nawrot, J. (2008). Molecular techniques for the detection of granary weevil (Sitophilus granarius L.) in wheat and flour. Food Additives and Contaminants Part A Chemistry Analysis Control Exposure \& Risk Assessment, 25, 1179-1188.

Parkin, E. A. (1956). Stored product enomology (the assessment and reduction of losses 650 caused by insects to stored foodstuffs). Annual Review of Entomology, 1, 223-

Phillips, T. W., \& Throne, J. E. (2010). Biorational approaches to managing storedproduct insects, annual review of entomology. Annual Review of Entomology, 55, $375-397$. 
663 Pimentel, D., Wilson, C., McCullum, C., Huang, R., Dwen, P., Flack, J., et al. (1997). Economic and environmental benefits of biodiversity. BioScience, 47, 747-757.

665

666

667

668

669

670

671

672

673

674

675

676

677

678

679

680

681

682

683

684

685

Riudavets, J., Castañé, C., Alomar, O., Pons, Mª J., \& Gabarra, R. (2009). Modified atmosphere packaging (MAP) as an alternative measure for controlling nine pests that attack processed food products. Journal of Stored Products Research, 45(2), $91-96$.

Shah, M. A., \& Khan, A. A. (2014). Imaging techniques for the detection of stored product pests. Applied Entomology and Zoology, 49, 201-212.

Solà, M., Agusti, N., \& Riudavets, J. (2015). Molecular approaches based on PCR to identify and quantify arthropod internal feeders in grain. Integrated Protection of Stored Products IOBC-WPRS Bulletin, 111, 387-393.

Solà, M., Lundgren, J.G., Agusti, N., \& Riudavets, J. (2017). Detection and quantification of the insect pest Rhyzopertha dominica (F.) (Coleoptera: Bostrichidae) in rice by qPCR. Journal of Stored Product Pests, 71, 106-111.

Stejskal, V., Aulicky, R., \& Kucerova, Z. (2014). Pest control strategies and damage potential of seed-infesting pests in the Czech stores: A review. Plant Protection Science, 50, 165-173.

Stejskal, V., Hubert, J., Aulicky, R., \& Kucerova, Z. (2015). Overview of present and past and pest-associated risks in stored food and feed products: European perspective. Journal of Stored Products Research, 64, 122-132.

Storey, C. L., Sauer, D. B., Ecker, O., \& Fulk, D. W. (1982). Insect infestations in wheat and corn exported from the United-States. Journal of Economic Entomology, 75, $827-832$. 
Toews, M. D., Campbell, J. F., Arthur, F. H., \& Ramaswamy, S. B. (2006). Outdoor flight activity and immigration of Rhyzopertha dominica into seed wheat warehouses. Entomologia Experimentalis et Applicata, 121, 73-85.

Toews, M. D., Perez-Mendoza, J., Throne, J. E., Dowell, F. E., Maghirang, E., Arthur, F. H., \& Campbell, J. F. (2007). Rapid assessment of insect fragments in flour milled from wheat infested with known densities of immature and adult Sitophilus oryzae (Coleoptera: Curculionidae). Journal of Economic Entomology, 100, 1714-1723.

Trematerra, P. (2013). Aspects related to decision support tools and integrated pest management in food chains. Food Control, 34, 733-742.

Trematerra, P., Stejskal, V., \& Hubert, J. (2011). The monitoring of semolina contamination by insect fragments using the light filth method in an Italian mill. Food Control, 22, 1021-1026.

Trematerra, P., Ianiro, R., Athanassiou, C. G., \& Kavallieratos, N. G. (2015). Behavioral 699 interactions between Sitophilus zeamais and Tribolium castaneum: The first colonizer matters. Journal of Pest Science, 88, 573-581.

Velebit, B., Markovic, B., Jankovic, V., \& Borovic, B., (2009). Identification of animal species in heat treated muscle homogenates using the polymerase chain reaction. Acta Veterinaria (Belgrad), 59(2-3), 303-308.

Zeale M. R. K, Butlin, R. K., Barker G. L. A., Lees, D. C., \& Jones G. (2011). Taxonspecific PCR for DNA barcoding arthropod prey in bat faeces. Molecular Ecology barcoding, species-specific PCR and real-time PCR techniques for the identification of Six Tribolium pests of stored products. Scientific Reports, 6, article number: 28494. 
Table 1. Insect species potentially present in stored grain products and tested for specificity with the developed multiplex PCR protocol. In bold, the five target species $(n>10)$. The order, family, origin, collection year and universal primer pair set used as positive control for the presence of DNA are indicated. Three specimens of each non-target species were tested, except for Trogoderma glabrum (n=2), Dinerella agra and Alphitobius laevigatus $(\mathrm{n}=1)$.

\begin{tabular}{|c|c|c|c|c|c|}
\hline Order & Family & Species & Origin & Collection year & Universal primer set* \\
\hline \multirow[t]{15}{*}{ Coleoptera } & \multirow[t]{2}{*}{ Anobiidae } & Lasioderma serricorne (Fabricius) & lab colony (IRTA), Spain & 2013 & ZBJ-ARTF1c/ZBJ-ArtR2c \\
\hline & & Stegobium paniceum (Linnaeus) & field sample, Spain & 2002 & ZBJ-ARTF1c/ZBJ-ArtR2c \\
\hline & \multirow[t]{4}{*}{ Bostrychidae } & Lyctus brunneus (Stephens) & field sample, Spain & 2003 & Uni-MinibarF1/Uni-MinibarR1 \\
\hline & & Dinoderus minutus (Fabricius) & field sample, Vietnam & 2002 & Uni-MinibarF1/Uni-MinibarR1 \\
\hline & & Rhyzopertha dominica (Fabricius) & $\begin{array}{l}\text { lab colony (IRTA), } \\
\text { Spain** }\end{array}$ & 2013 & ZBJ-ARTF1c/ZBJ-ArtR2c \\
\hline & & Prostephanus truncatus (Horn) & field sample, Mexico & 2010 & ZBJ-ARTF1c/ZBJ-ArtR2c \\
\hline & \multirow[t]{2}{*}{ Bruchidae } & Acanthoscelides obtectus (Say) & lab colony (IRTA), Spain & 2013 & ZBJ-ARTF1c/ZBJ-ArtR2c \\
\hline & & Zabrotes subfasciatus (Boheman) & lab colony (IRTA), Spain & 2013 & ZBJ-ARTF1c/ZBJ-ArtR2c \\
\hline & Chrysomelidae & Callosobruchus maculatus (Fabricius) & lab colony (IRTA), Spain & 2013 & ZBJ-ARTF1c/ZBJ-ArtR2c \\
\hline & Cleridae & Necrobia rufipes (Fabricius) & field sample, Spain & 2010 & ZBJ-ARTF1c/ZBJ-ArtR2c \\
\hline & \multirow[t]{3}{*}{ Curculionidae } & Sitophilus granarius (Linnaeus) & $\begin{array}{l}\text { lab colony (IRTA), } \\
\text { Spain** }\end{array}$ & 2013 & ZBJ-ARTF1c/ZBJ-ArtR2c \\
\hline & & Sitophilus oryzae (Linnaeus) & $\begin{array}{l}\text { lab colony (IRTA), } \\
\text { Spain** }\end{array}$ & 2013 & ZBJ-ARTF1c/ZBJ-ArtR2c \\
\hline & & Sitophilus zeamais (Motschulsky) & $\begin{array}{l}\text { lab colony (IRTA), } \\
\text { Spain** }\end{array}$ & 2013 & ZBJ-ARTF1c/ZBJ-ArtR2c \\
\hline & \multirow[t]{2}{*}{ Dermestidae } & Dermestes haemorrhoidalis (Küster) & field sample, Spain & 2006 & ZBJ-ARTF1c/ZBJ-ArtR2c \\
\hline & & Dermestes maculatus (DeGeer) & field sample, Spain & 2011 & ZBJ-ARTF1c/ZBJ-ArtR2c \\
\hline
\end{tabular}




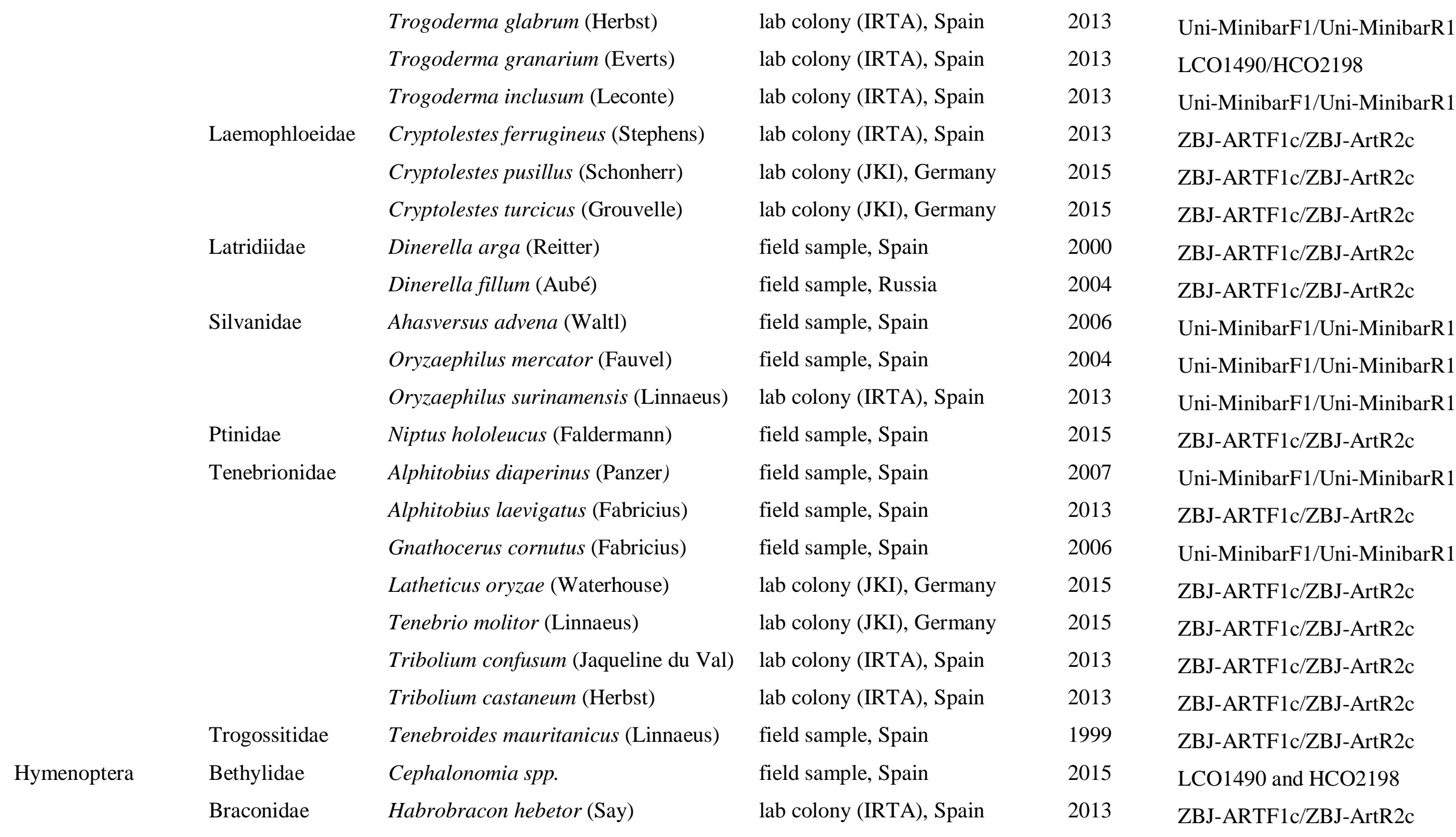




\begin{tabular}{|c|c|c|c|c|c|}
\hline & Ichneumonidae & Venturia canescens (Gravenhorst) & lab colony (IRTA), Spain & 2013 & ZBJ-ARTF1c/ZBJ-ArtR2c \\
\hline & Pteromalidae & Anisopteromalus calandrae (Howard) & lab colony (IRTA), Spain & 2013 & ZBJ-ARTF1c/ZBJ-ArtR2c \\
\hline & & Lariophagus distinguendus (Förster) & lab colony (IRTA), Spain & 2013 & ZBJ-ARTF1c/ZBJ-ArtR2c \\
\hline \multirow[t]{6}{*}{ Lepidoptera } & Pyralidae & Ephestia cautella (Walker) & lab colony (JKI), Germany & 2015 & ZBJ-ARTF1c/ZBJ-ArtR2c \\
\hline & & Ephestia elutella (Hübner) & lab colony (JKI), Germany & 2015 & ZBJ-ARTF1c/ZBJ-ArtR2c \\
\hline & & Ephestia kuehniella (Zeller) & lab colony (IRTA), Spain & 2013 & ZBJ-ARTF1c/ZBJ-ArtR2c \\
\hline & & Plodia interpunctella (Hübner) & lab colony (IRTA), Spain & 2013 & ZBJ-ARTF1c/ZBJ-ArtR2c \\
\hline & Gelechiidae & Sitotroga cerealella (Olivier) & $\begin{array}{l}\text { lab colony (IRTA), } \\
\text { Spain** }\end{array}$ & 2013 & ZBJ-ARTF1c/ZBJ-ArtR2c \\
\hline & Tineidae & Nemapogon granella (Linnaeus) & field sample, Spain & 1999 & ZBJ-ARTF1c/ZBJ-ArtR2c \\
\hline Mesostigmata & Ascidae & Blattisocius tarsalis (Berlese) & lab colony (IRTA), Spain & 2001 & Uni-MinibarF1/Uni-MinibarR1 \\
\hline Pseudoscorpionida & Withiidae & Withius piger (Simon) & field sample, Spain & 2011 & ZBJ-ARTF1c/ZBJ-ArtR2c \\
\hline Psocoptera & Liposcelididae & Liposcelis botrichophila (Badonnel) & field sample, Spain & 1997 & LCO1490/HCO2198 \\
\hline \multirow[t]{2}{*}{ Sarcoptiforme } & Acaridae & Tyrophagus perniciosus (Zakhvatkin) & lab colony (IRTA), Spain & 2013 & ZBJ-ARTF1c/ZBJ-ArtR2c \\
\hline & & Tyrophagus putrecentiae (Schrank) & field sample, Spain & 1997 & LCO1490/HCO2198 \\
\hline
\end{tabular}

* ZBJ-ArtF1c/ZBJ-ArtR2c (Zeale et al., 2011); Uni-MinibarF1/Uni-MinibarR1 (Meusnier et al., 2008); LCO1490/HCO2198 (Folmer et al., 1994).

** The species coming from laboratory colonies (IRTA) were originally from Tarragona, Spain. 
Table 2. Specific primer pairs designed for each target species. The corresponding primer concentration $(\mu \mathrm{M})$ used in the primer mix and the number of base pairs (bp) amplified are also indicated.

\begin{tabular}{|c|c|c|c|}
\hline Target species & Primer name and sequence ( $\left.5^{\prime}-3^{\prime}\right)$ & $\begin{array}{c}\text { Primer } \\
\text { concentration } \\
(\mu \mathrm{M})\end{array}$ & $\begin{array}{c}\text { Amplicon } \\
\text { size (bp) }\end{array}$ \\
\hline \multirow[t]{2}{*}{ S. cerealella } & SCF4: GATACTTATTACGTAGTTGCTC & 0.4 & 93 \\
\hline & SCR4: TAAGGGGTATCAATGAATG & 0.4 & \\
\hline \multirow[t]{2}{*}{ S. zeamais } & SZF2: CTCCCTCCATCATTAATTC & 0.6 & 151 \\
\hline & SZR3: TACCTGCTATATGAAGAC & 0.6 & \\
\hline \multirow[t]{2}{*}{ S. oryzae } & SOF4: TGGAAACTGATTAATCCCAT & 0.1 & 213 \\
\hline & SOR2: CTGAAAATGGCCAGATCAAC & 0.1 & \\
\hline \multirow[t]{2}{*}{ R. dominica } & RDF1: GCTTCTTCCАCCСТCCTTAАCC & 0.6 & $286^{*}$ \\
\hline & RDR1: AGATAATAATAAAAGCAAAGC & 0.6 & \\
\hline \multirow[t]{2}{*}{ S. granarius } & SGF1: CGTTACTGCTCACGCATTT & 0.2 & 452 \\
\hline & SGR1: TAGTAATTGCTCTAGCTAAG & 0.2 & \\
\hline
\end{tabular}

* Designed by Solà et al. (2017). 
Table 3. Frequencies (\%) of multiplex PCR amplification per each insect species at four different infestation doses (pupae/Kg of rice) and six post-mortem periods of time (days).

Two replicates have been done for infestation dose, and three for time post mortem.

\begin{tabular}{|c|c|c|c|c|c|c|c|c|c|c|}
\hline \multirow[b]{2}{*}{ Species } & \multicolumn{4}{|c|}{ Infestation dose $(\mathrm{p} / \mathrm{Kg})$} & \multicolumn{6}{|c|}{ Time post-mortem (d) } \\
\hline & 100 & 10 & 1 & 0.1 & 30 & 90 & 150 & 365 & 548 & 760 \\
\hline Sitotroga cerealella & 100 & 100 & 100 & 100 & 100 & 100 & 100 & 100 & 100 & 100 \\
\hline Sitophilus zeamais & 100 & 100 & 100 & 100 & 100 & 100 & 100 & 100 & 100 & 100 \\
\hline Sitophilus oryzae & 100 & 100 & 100 & 100 & 100 & 100 & 100 & 100 & 100 & 100 \\
\hline Sitophilus granarius & 100 & 100 & 100 & 100 & 100 & 100 & 100 & 100 & 67 & 0 \\
\hline Rhyzopertha dominica & 100 & 100 & 0 & 0 & 100 & 100 & 100 & 100 & 33 & 0 \\
\hline
\end{tabular}


Figure 1. Agarose gel electrophoresis of the PCR products amplified with the designed multiplex PCR. M: molecular marker (100 bp ladder). C+: Positive control of the 5 target species (mixture of $1 \mu 1$ of DNA extraction of each of the target species in $15 \mu 1$ of purified water). SC: S. cerealella, SZ: S. zeamais, SO: S. oryzae, RD: $R$. dominica, SG: S. granarius, C-: Negative control (purified water).

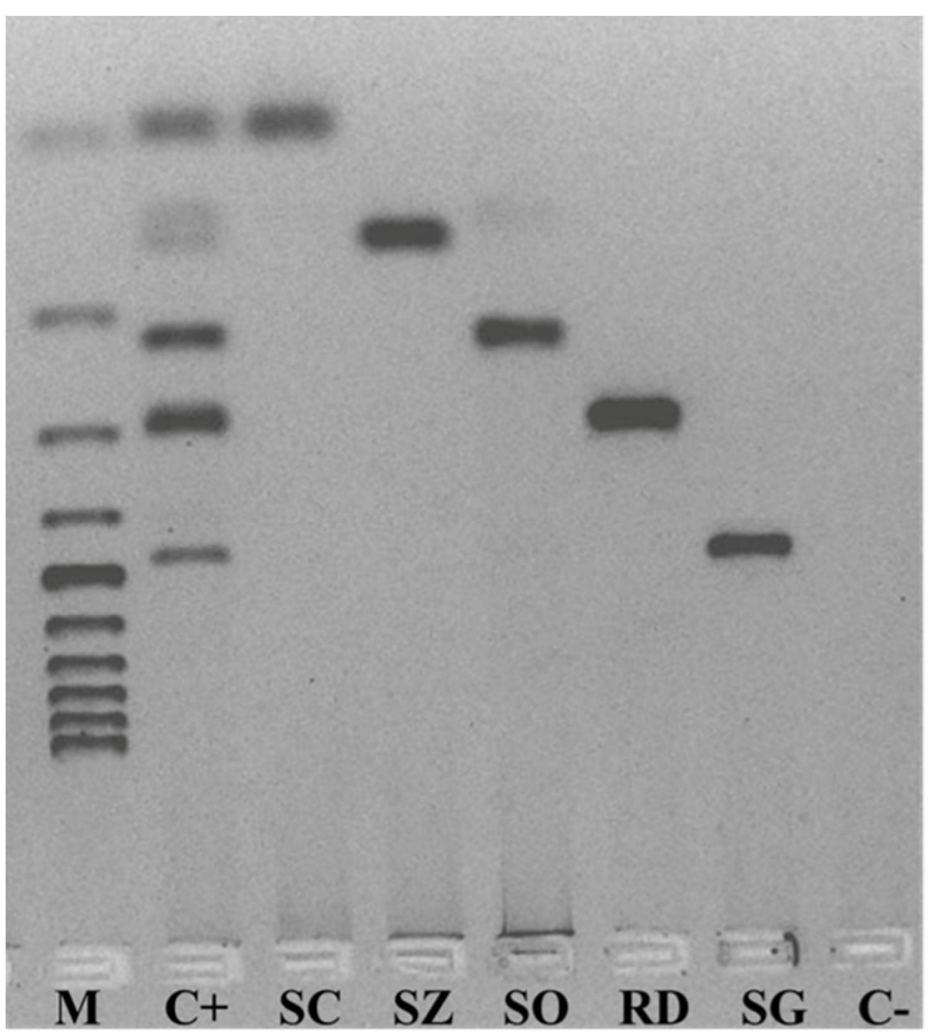


Figure S1. PCR products obtained when testing the sensitivity of the designed multiplex PCR with the five internal feeders ( $S$. cerealella, $S$. zeamais, $S$. oryzae, $R$. dominica, $S$. granarius) in different artificial pupae infestation doses in rice (100: 100 pupae/Kg, 10: 10 pupae/Kg, 1: 1 pupae/Kg, 0.1: 0.1 pupae/kg, C+: positive control of the 5 target species (mixture of $1 \mu$ l of DNA extraction of each of the target species in $15 \mu 1$ of purified water), C-: negative control (purified water), M: molecular marker (100 bp ladder)).

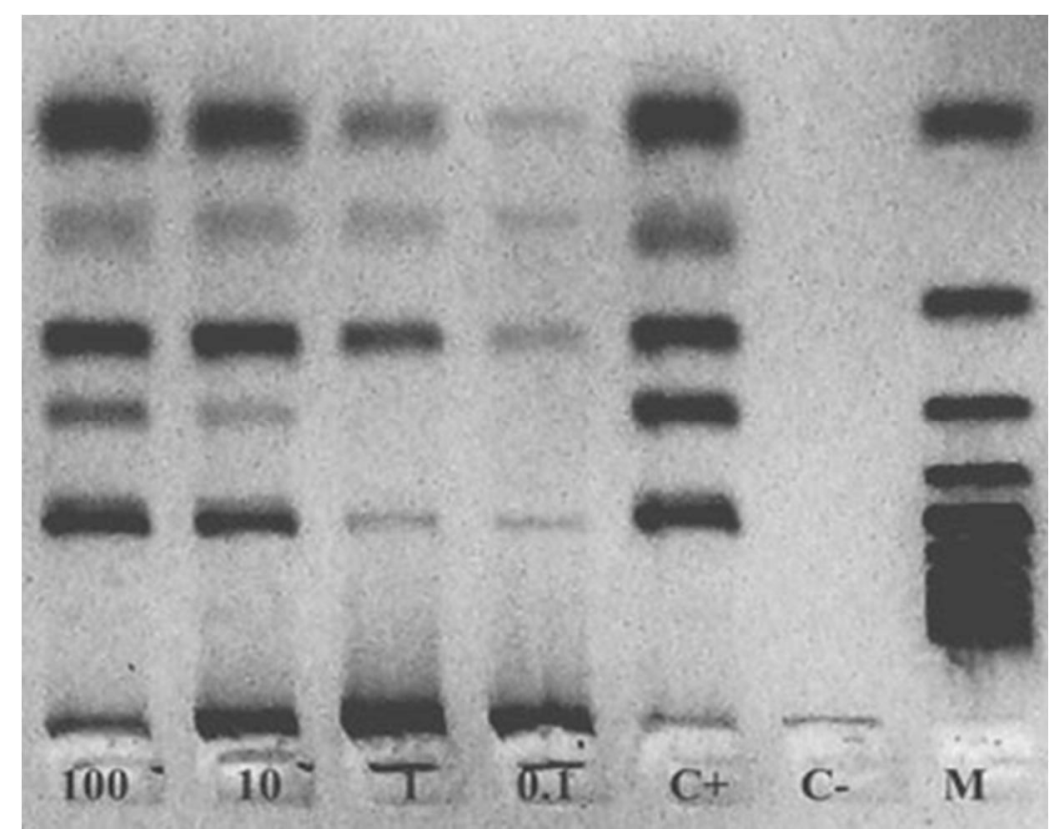


Figure S2. PCR products amplified from the five internal feeders ( $S$. cerealella, $S$. zeamais, $S$. oryzae, $R$. dominica, $S$. granarius) after different post-mortem periods (M: molecular marker (100 bp ladder); C+: positive control of the 5 target species (mixture of $1 \mu \mathrm{l}$ of DNA extraction of each of the target species in $15 \mu \mathrm{l}$ of purified water); $\mathbf{C}-\mathbf{\text { : }}$ negative control purified water); 30, 90, 150, 360, 548 and 760: number of days postmortem).

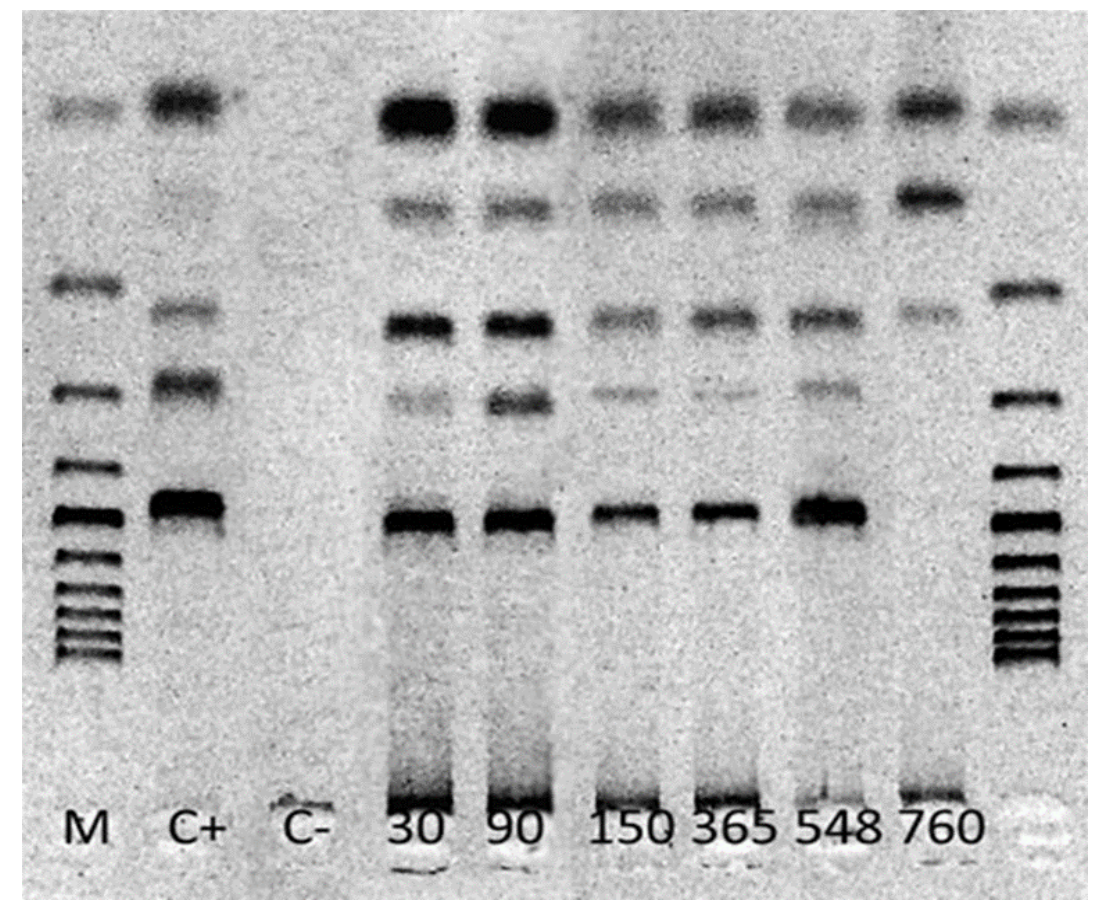


Figure S3. Agarose gel electrophoresis of the DNA amplification of Sitophilus zeamais larvae in different cereals (M: molecular marker (100 bp ladder); C-: negative control (purified water); 1: spelt, 2: wheat, 3: rice, 4: oat, 5: barley, 6: pasta, 7: maize).

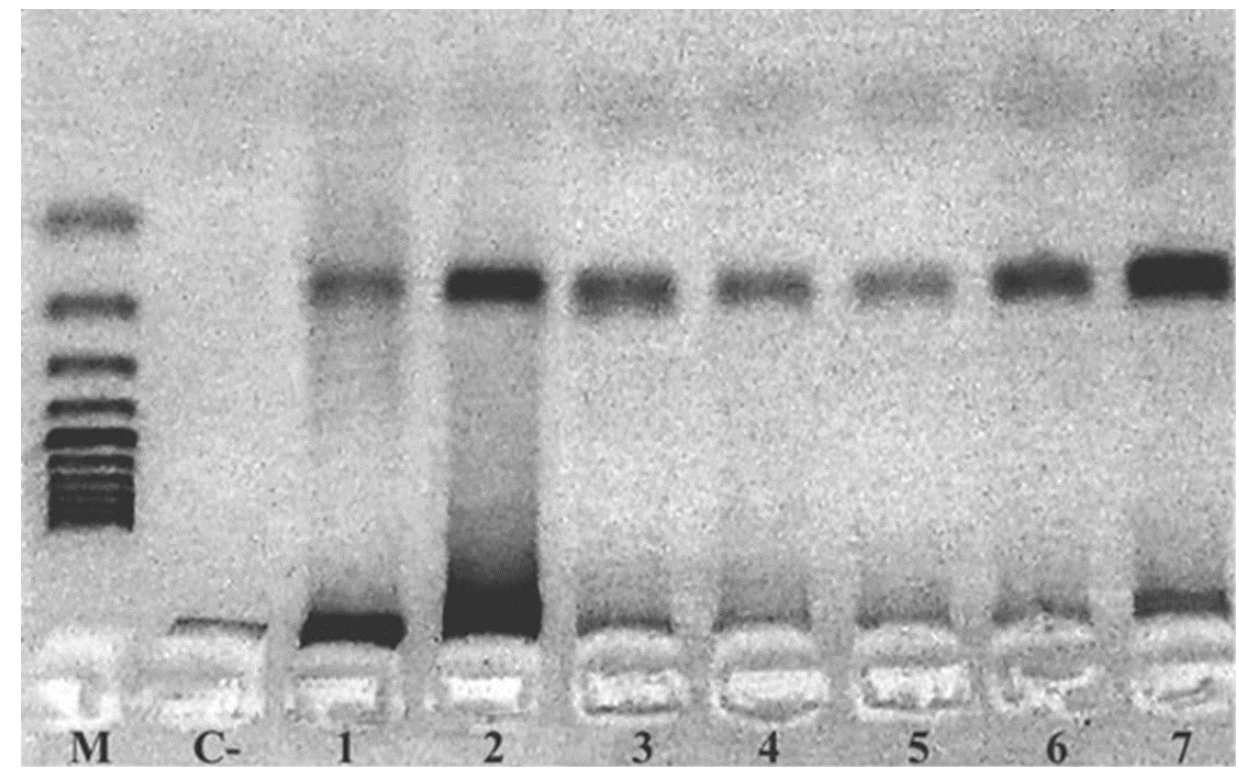

